\title{
PEMUTIHAN KERTAS KORAN BEKAS DENGAN MENGGUNAKAN ASAM PEROKSIDA DALAM MEDIA ASAM ASETAT
}

\author{
Sri Hidayati ${ }^{1{ }^{*}}$, Ahmad Sapta Zuidar ${ }^{1)}$ dan Rachmania Widyastuti ${ }^{2)}$ \\ 1 ) Dosen Jurusan Teknologi Hasil Pertanian Fakultas Pertanian Universitas Lampung Jl. \\ Prof. Soemantri Brojonegoro No. 1 Bandar Lampung, Lampung 35145 \\ 2) Alumni Jurusan Teknologi Hasil Pertanian, Fakultas Pertanian, Universitas Lampung \\ Penulis korespondensi: srihidayati.unila@gmail.com
}

\begin{abstract}
Used newsprint is one of the most potential materials to be recovered into pulp raw material. The problem is the color of newsprint that requires bleaching process. One of the oxidizing agents used for bleaching is the peroxide acid in the acetic acid medium. The purpose of this research is to know the effect of peroxide acid concentration in acetic acid media and the duration of heating to the chemical properties of pulp produced. The best results were obtained at $12 \%$ per oxide acid concentration in acetic acid medium and 5 hour heating time, yielding $58.653 \%$ cellulose, hemicellulose $9.033 \%$, lignin $22.683 \%$, and color score $4.503 \%$ (rather white).
\end{abstract}

\section{Keywords: cellulose, hemicelulose, lignine}

\section{PENDAHULUAN}

Pembuatan pulp dan kertas di Indonesia menggunakan kayu hutan seperti pinus sehingga menimbulkan banyak masalah terutama penggundulan hutan dan isu pemanasan global serta semakin menipisnya cadangan kayu dan luas hutan di Indonesia (Deperindag dan APKI, 2001, Barr, 2001; Arifin, 2008; Madakadze et al., 1999; Aremu et al., 2015). Laju kerusakan hutan diperkirakan mencapai 450.000 ha/tahun (Kemenhut, 2013) dimana terjadi penurunan luasan hutan sebesar $85 \%$ atau 10.2 juta ha di Sumatera (Yves et al. 2010) akibat pengundulan hutan dan dilegalkannya pemanfaatan lahan dan sumberdaya hutan terbatas (Yamani, 2011). Oleh karena itu, pemerintah perlu mencari alternatif bahan lain yang dapat dimanfaatkan sebagai bahan baku pulp dan kertas selain kayu. Salah satu alternatif untuk mengatasi kelangkaan dan mahalnya bahan baku kertas dari pulp asli (virgin pulp), yaitu dengan pemakaian kembali kertas bekas sebagai bahan baku kertas (Rismijana et al., 2003). Kertas koran merupakan limbah yang cukup potensial untuk dimanfaatkan kembali menjadi kertas.

Keunggulan dari kertas bekas (sekunder) untuk pembuatan kertas cetak antara lain meningkatkan stabilitas dimensi, dapat meningkatkan opasitas cetak, mengurangi kecenderungan kertas untuk mengerut atau menggulung, memperbaiki formasi kertas, dan memperbaiki retensi kertas. Kekurangannya antara lain derajat putih dan kekuatan yang relatif rendah, mengandung kontaminan yang beragam dan derajat giling yang tidak seragam, serta seratnya relatif pendek (Mahagaonkar dan Paul, 1995). Koran bekas kontaminan utamanya adalah tinta cetak yang umumnya terdiri dari pigmen atau butiran tinta yang berperan sebagai pembawa warna berbentuk partikel padatan kecil. Vehicle atau zat pembawa pigmen berfungsi mengalirkan pigmen tinta pada kertas selama pencetakan 
sehingga dapat berikatan dengan serat. Vehicle umumnya berupa resin, minyak nabati dan larutan volatil (Paraskevas, 1990). Untuk menghilangkan sisa warna dapat digunakan dengan cara oksidasi yang diikuti dengan reaksi pemutihan (bleaching). Salah satu oksidator yang dapat menghilangkan warna adalah asam peroksida di dalam media asam asetat atau yang dikenal dengan perasetat (Sun et al, 2000).

Berdasarkan sifat dari hidrogen peroksida sebagai bahan pemutih dan kondisi proses pemutihan maka diharapkan dapat mengurangi kandungan lignin dan meningkatkan derajat kecerahan pulp dari kertas bekas (Wildan et al, 2010). Tujuan proses pemutihan pada pulp adalah untuk menaikkan derajat putih dengan cara menghilangkan komponen kromofor yang menyerap sinar di dalam pulp, terutama gugus fungsional lignin yang terdegradasi dan sisa lignin yang telah diubah. Pemutihan dapat meningkatkan perubahan sifat sifat optik pulp terhadap penyerapan sinar, penghamburan sinar dan pemantulan yang dinyatakan dalam derajat putih pulp.(Wildan et al, 2010). Proses pemutihan Proses pemutihan pulp juga dapat meningkatkan kebersihan pulp dengan cara menghilangkan ekstraktifekstraktif dan zat-zat yang menyebabkan pulp menjadi kotor, yang meliputi kotoran-kotoran anorganik dan sisa kulit. Di dalam pembuatan pulp sebagai bahan dasar kertas yang bermutu tinggi, keberadaan hemiselulosa menjadi sangat penting, sementara pada pulp larutan, keberadaan hemiselulosa ini justru memiliki pengaruh yang buruk. Pemutih kertas biasanya menggunakan oxidizing agent atau reduching agent yang dapat menghilangkan atau memecahkan senyawa kromofor aromatik. Oksidan yang digunakan adalah senyawa klorin, hidrogen peroksida, sodium perborat, potassium permangat dan ozon, sedangkan reduktan yang biasa digunakan adalah sulfur dioksida dan senyawa sodium (Jayanudin, 2010). Proses pemutihan serat harus menggunakan bahan kimia yang reaktif untuk melarutkan kandungan lignin yang ada di dalam serat agar diperoleh derajat kecerahan yang tinggi. Namun demikian, harus dijaga agar penggunaan bahan kimia tersebut tidak menyebabkan pencemaran lingkungan yang berbahaya (Batubara, 2006). Proses pemutihan diaplikasikan menggunakan beberapa tahap (multi tahap) untuk memperoleh pulp yang memiliki derajat putih yang sangat tinggi dan stabil. Proses pemutihan dengan multi tahap merupakan sebuah metode pemurnian pulp dengan cara menambahkan bahan kimia pemutih dan pemurni dalam beberapa tahap yang dipisahkan dengan perlakuan pencucian dengan air atau alkali diantaranya, di mana hasil reaksi akan dikeluarkan dalam perlakuan pencucian. Retnowati (2008) menggunakan asam peroksida sebanyak $4 \%$ pada pemutihan enceng gondok sedangkan Edahwati (2009) melaporkan bahwa penggunaan asam peroksida pada konsentrasi 3\% menghasilkan derajat putih sebesar 58.75\% dan Fuadi (2008) menunjukkan bahwa pemutihan menggunakan peroksida $16 \%$ adalah yang terbaik untuk pulp dari akasia.

Keuntungan menggunakan $\mathrm{H}_{2} \mathrm{O}_{2}$ dalam media asam asetat adalah tidak merusak selulosa dan bebas klor sehingga tidak berbahaya bagi lingkungan (Sofian, 2011). Zuidar et al (2014) melaporkan bahwa penggunaan konsentrasi $\mathrm{H}_{2} \mathrm{O}_{2}$ dalam media asam asetat terbaik pada pulp dari TKKS diperoleh dari konsentrasi asam peroksida di dalam media asam asetat $15 \%$ dengan nilai rendemen $84.852 \%$, selulosa $84.494 \%$, hemiselulosa $6.319 \%$, lignin $5.691 \%$ serta nilai rata-rata organoleptik warna 4.017 (putih kekuningan). 


\section{METODE}

\section{Alat dan Bahan}

Alat-alat yang digunakan dalam penelitian ini yaitu baskom, oven, penangas, timbangan, cawan porselen, desikator, corong, serta alat-alat gelas untuk analisis kimia pulp.

Bahan-bahan yang digunakan yaitu koran bekas, asam asetat, $\mathrm{H}_{2} \mathrm{O}_{2}, \mathrm{H}_{2} \mathrm{SO}_{4}$ $1 \mathrm{~N}, \mathrm{H}_{2} \mathrm{SO}_{4} 72 \%$, air suling, kertas saring, alumunium foil, serta bahan analisis lainnya.

\section{Metode Penelitian}

Percobaan disusun secara faktorial dalam Rancangan Acak Kelompok Lengkap (RAKL) dengan tiga ulangan yang terdiri dari dua faktor yaitu konsentrasi larutan pemasak ( asam peroksida di dalam media asam asetat ) $\mathrm{K} 10 \%(\mathrm{v} / \mathrm{v}), \mathrm{K} 23 \%$ (v/v), K3 6\% (v/v), K4 9\%, K5 12\%, (v/v), K6 15\% (v/v), K7 $18 \%(\mathrm{v} / \mathrm{v})$ dan faktor kedua, yaitu lama pemasakan L1 (3 jam) dan L2 (5 jam). Kesamaan ragam diuji dengan uji Bartlett dan kemenambahan data diuji dengan uji Tuckey. Data dianalisis dengan sidik ragam untuk mendapatkan penduga ragam galat dan uji signifikansi untuk mengetahui ada tidaknya perbedaan antar perlakuan. Data kemudian dianalisis lebih lanjut dengan Duncan test pada taraf $1 \%$ dan 5\% (Steel dan Torrie, 1995).

\section{Pelaksanaan Penelitian Pembuatan Pulp}

Penghancuran kertas koran bekas (100 gram) dengan penambahan air, dengan perbandingan air dan kertas (3: $1)$.

\section{Pembuatan asam peroksida di dalam media asam asetat}

Asam peroksida di dalam media asam asetat dibuat berdasarkan reaksi antara asam asetat glacial $98 \%(\mathrm{v} / \mathrm{v})$ dan hidrogen peroksida konsentrasi 50\% (v/v).

\section{Pemutihan Pulp}

Pemutihan terhadap pulp dengan menggunakan perlakuan perbedaan konsentrasi asam peroksida di dalam media asam asetat dan lama pemasakan. Pulp dipanaskan dalam gelas piala dengan konsentrasi perlakuan pada suhu $85^{\circ} \mathrm{C}$ selama 3 dan 5 jam dengan perbandingan asam peroksida di dalam media asam asetat:kertas 3:1, kemudian dilakukan pencucian memakai air dengan cara penyaringan (100 mesh).

\section{Pengamatan}

Pulp yang diperoleh kemudian diuji rendemen dan sifat kimianya. Sifat kimia yang diuji meliputi kadar selulosa, hemiselulosa, lignin. Analisis selulosa, hemiselulosa dan lignin dengan menggunakan metode Datta (1981), yaitu sebagai berikut:

Sebanyak 2 gram bahan kering (berat konstan) dimasukkan dalam gelas Beker dan ditambah aquades $150 \mathrm{ml}$. Panaskan selama 2 jam di dalam penangas dengan suhu $100^{\circ} \mathrm{C}$. Saring dan cuci dengan aquades sampai volume filtrat $300 \mathrm{ml}$, kemudian residu dikeringkan pada oven bersuhu $105^{\circ} \mathrm{C}$ hingga beratnya konstan (a). Residu kering (a) dimasukkan kedalam erlenmeyer $250 \mathrm{ml}$ ditambah $150 \mathrm{ml} \mathrm{H}_{2} \mathrm{SO}_{4} 1 \mathrm{~N}$, kemudian di panaskan pada penangas air $100^{\circ} \mathrm{C}$ selama 1 jam, kemudian dilakukan penyaringan dan residu dicuci dengan aquades panas sampai volume filtrat $300 \mathrm{ml}$. Residu dikeringkan hingga beratnya konstan dan ditimbang (b), selanjutnya residu kering (b) dimasukkan lagi ke dalam erlenmeyer $250 \mathrm{ml}$ dan ditambahkan $10 \mathrm{ml} \mathrm{H}_{2} \mathrm{SO}_{4}$ $72 \%$, direndam selama 4 jam pada suhu kamar kemudian ditambahkan $150 \mathrm{ml}$ $\mathrm{H}_{2} \mathrm{SO}_{4} 1 \mathrm{~N}$, dipanaskan pada penangas air suhu $100^{\circ} \mathrm{C}$ selama 2 jam. Dilakukan penyaringan dan di cuci dengan aquades panas hingga volume filtrat $400 \mathrm{ml}$. Residu dikeringkan hingga beratnya konstan dan di timbang (c). Residu (c) 
tersebut kemudian diabukan selama 6 jam $\left(600^{\circ} \mathrm{C}\right)$. Kadar Hemiselulosa dapat dihitung dengan rumus:

$$
\text { Hemiselulosa }(\%)=\frac{a-b}{\text { berat } \text { sampel }} \times 100
$$

Kadar Selulosa dapat dihitung dengan rumus:

$$
\text { Selulosa }(\%)=\frac{b-c}{\text { berat sampel }} \times 100
$$

Kadar Lignin dapat dihitung dengan rumus:

$$
\operatorname{Lignin}(\%)=\frac{c-\text { berat abu }}{\text { berat sampel }} \times 100
$$

Sebagai indikator berkurangnya kadar lignin, maka dilakukan uji organoleptik terhadap warna pulp kertas koran bekas. Pengujian dilakukan berdasarkan metode skoring.

\section{HASIL DAN PEMBAHASAN}

\section{Hemiselulosa}

Kadar hemiselulosa yang dihasilkan dari penelitian ini berkisar dari $5.683 \%$ sampai $23.467 \%$. Hasil analisis ragam menunjukkan bahwa penambahan konsentrasi asam peroksida di dalam media asam asetat, lama pemasakan dan interaksi keduanya berpengaruh sangat nyata terhadap kadar hemiselulosa pulp kertas koran bekas. Uji lanjut Duncan menunjukkan bahwa pulp kertas koran bekas dengan konsentrasi asam peroksida di dalam media asam asetat $0 \%$ dan lama pemasakan selama 3 jam tidak berbeda nyata dengan pulp kertas koran bekas dengan konsentrasi asam peroksida di dalam media asam asetat $3 \%$ dan $18 \%$, sedangkan perlakuan dengan konsentrasi $0 \%$ dan lama pemasakan selama 5 jam tidak berbeda nyata dengan penggunaan asam peroksida di dalam media asam asetat konsentrasi 3\% dan 6\% (Gambar 1).

Penurunan kadar hemiselulosa dikarenakan lama reaksi merupakan salah satu faktor yang mempengaruhi banyaknya hidrolisis asam terhadap hemiselulosa, selain bentuk ikatan glikosida, aksesibilitas hemiselulosa, konsentrasi asam, dan suhu. Reaksi hidrolisis dalam suasana asam menyebabkan penyusutan rantai samping galaktosa dan arabinosa dan penurunan derajaat polimerisasi secara bertahap dalam proses sulfit asam (Achmadi, 1990). Menurut Fengel dan Wegener (1995), hemiselulosa mudah didegradasi menjadi unit-unit yang lebih sederhana dan mudah larut air karena berbentuk non kristal. Selain itu, Sjostrom (1981) menyatakan bahwa ikatan-ikatan glikosida yang terdapat pada hemiselulosa sangat sensitif terhadap hidrolisis yang bersifat asam. Hemiselulosa juga lebih mudah diserang dibandingkan dengan selulosa, karena derajat polimerisasinya relatif rendah dan ikatan glikosidanya sangat labil terhadap hidrolisis yang bersifat asam (Hill et al, 1992) Penelitian Hatakeyama et al (1986) menunjukkan bahwa reaksi antara asam peroksida di dalam media asam asetat dengan monodan polisakarida diperoleh hasil bahwa xilan dan mannan dari hemiselulosa lebih mudah terputus bila dibandingkan dengan selulosa. Degradasi karbohidrat pulpa terutama bergantung pada konsentrasi peroksida dalam media asam asetat (Jaaskeláinen dan Poppiuslevlin, 1998). Degradasi kemungkinan disebabkan oleh spesies reaktif yang berasal dari reaksi dekomposisi perasetat, yang diintensifkan pada konsentrasi yang lebih tinggi. 


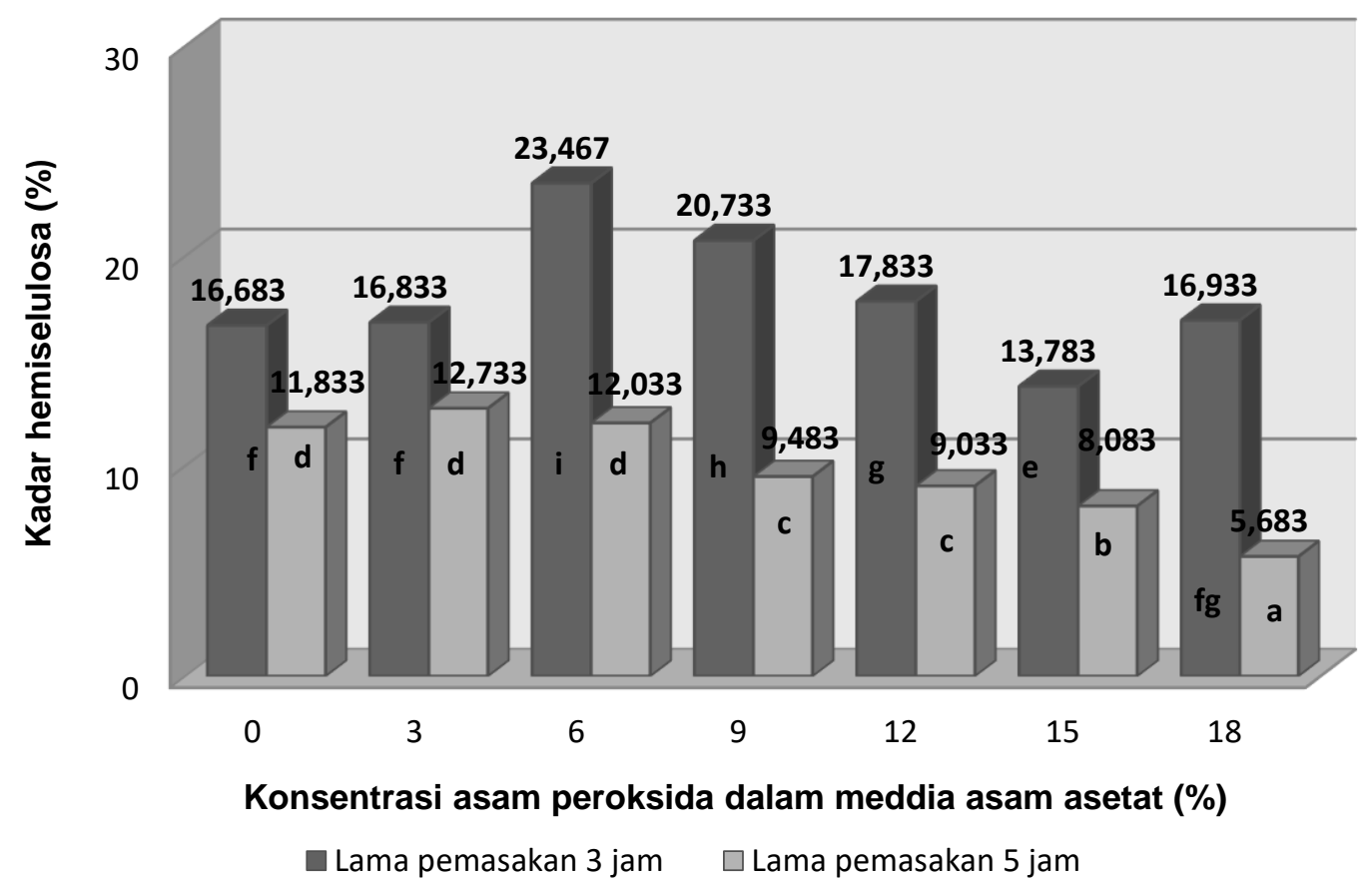

Keterangan: angka-angka yang diikutii oleh huruf yang sama tidak berbeda nyata pada taraf 5\%

Gambar 1. Kadar hemiselulosa dengan penambahan kosentrasi asam peroksida dalam media asam asetat sebanyak 0\% sampai 18\% dan lama pemasakan selama 3 jam dan 5 jam

\section{Selulosa}

Kadar selulosa yang dihasilkan dari penelitian ini berkisar dari $38.707 \%$ sampai 58.653\%. Hasil analisis ragam menunjukkan bahwa penambahan konsentrasi asam peroksida di dalam media asam asetat, lama pemasakan dan interaksi keduanya berpengaruh sangat nyata terhadap kadar selulosa pulp kertas koran bekas. Uji lanjut Duncan menunjukkan bahwa pulp kertas koran bekas dengan perlakuan asam peroksida di dalam media asam asetat 3\% dan lama pemasakan selama 3 jam tidak berbeda nyata dengan pulp kertas koran bekas dengan perlakuan asam peroksida di dalam media asam asetat $9 \%$, sedangkan perlakuan dengan konsentrasi 3\% dan lama pemasakan selama 5 jam tidak berbeda nyata dengan penggunaan asam peroksida di dalam media asam asetat $6 \%$. Kadar selulosa tertinggi dihasilkan pada konsentrasi asam peroksida di dalam media asam asetat $12 \%$ dan lama pemasakan selama 5 jam (Gambar 2).

Hasil penelitian Hidayati dan Zulferiyenni (2006) menyebutkan bahwa penggunaan asam peroksida di dalam media asam asetat sampai konsentrasi 9\% mampu meningkatkan kadar selulosa pulp kertas koran bekas dari $40 \%$ menjadi $60 \%$. Hal ini disebabkan asam peroksida di dalam media asam asetat yang digunakan merupakan bahan yang bersifat selektif, yang khusus menyerang lignin. Walaupun peroksida dari asam peroksida di dalam media asam asetat bersifat sebagai oksidator, tetapi selektif hanya merusak sedikit dan hasil penguraiannya berupa gula sederhana yang mudah larut dalam air, namun penggunaan asam peroksida di dalam media asam asetat yang berlebih dan konsentrasi yang lebih tinggi akan menyebabkan oksidasi 
polisakarida melalui pembentukan radikal hidroksi (Nevel dan Zerodian, 1985).

Hidrogen peroksida merupakan asam lemah dan bagian-bagian yang aktif adalah anion peroksida nukleofil $\left(\mathrm{H}_{2} \mathrm{O}^{-}\right)$ yang mengubah struktur karbonil dan mengubah sistem-sistem yang kurang bersifat kromofor dan tidak mengakibatkan degradasi selulosa (Sjostrom, 1981).

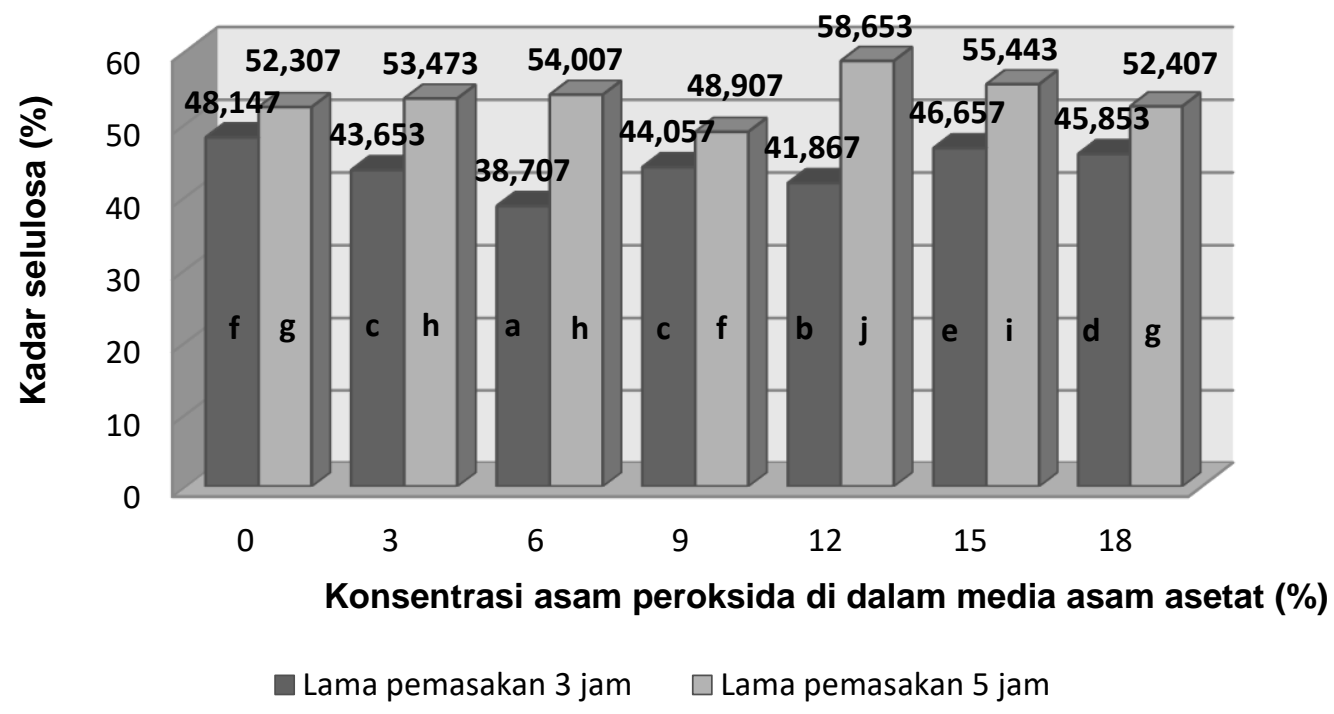

Keterangan: angka-angka yang diikuti oleh huruf yang sama tidak berbeda nyata pada taraf 5\%

Gambar 2. Kadar selulosa dengan penambahan konsentrasi asam peroksida di dalam media asam asetat sebanyak $0 \%$ sampai $18 \%$

\section{Lignin}

Kadar lignin yang dihasilkan dari penelitian ini berkisar dari $22.683 \%$ sampai $30.733 \%$. Hasil analisis ragam menunjukkan bahwa penambahan asam peroksida di dalam media asam asetat, lama pemasakan dan interaksi keduanya berpengaruh sangat nyata terhadap kadar lignin pulp kertas koran bekas. Uji lanjut Duncan menunjukkan bahwa pulp kertas koran bekas dengan perlakuan asam peroksida di dalam media asam asetat $12 \%$ dan lama pemasakan selama 5 jam berbeda nyata dengan pulp kertas koran bekas dengan perlakuan lainnya dan menghasilkan kadar lignin terendah, yaitu $22.683 \%$ (Gambar 3). Peningkatan konsentrasi asam peroksida adalam media asam asetat sampai $12 \%$ dapat menurunkan kadar ligin. Coniwati et al (2015) melaporkan bahwa Kadar lignin paling sedikit yaitu, $0.094 \%$ didapatkan pada kondisi temperatur proses bleaching $90^{\circ} \mathrm{C}$, selama 90 menit, dengan konsentrasi hidrogen peroksida $10 \%$. Jayanudin (2010) yang mengatakan temperatur dan waktu pemanasan mempengaruhi proses bleaching dimana semakin tinggi temperatur dan lamanya waktu pemanasan maka kandungan lignin pada produk akan semakin sedikit.

Peningkatan kadar lignin setelah penambahan konsentrasi asam peroksida dalam media asam asetat >15\% diduga akibat terjadinya kondensasi lignin. Achmadi (1990) menyatakan bahwa asam peroksida di dalam media asam asetat mampu mengoksidasi lignin, selain klor dioksida. Produk yang dihasilkan yaitu asam dikarboksilat jenis mukonat dan jenis flatat Lawrence et al, 1980). Pada suasana asam, lignin cenderung 
melakukan kondensasi. Peristiwa ini menyebabkan bobot molekul lignin bertambah dan dalam keadaan sangat asam, lignin yang terkondensasi ini mengendap. Asam peroksida di dalam media asam asetat merupakan zat pengoksidasi, oksidasi lignin oleh asam peroksida di dalam media asam asetat berjalan dalam jalur yang bersaing. Di antara jalur-jalur tersebut yang lebih menonjol adalah hidroksilasi cincin elektrofilik, demetilasi, pembentukan orto- dan para-kuinon, dan pemecahan cincin aromatis (Chang, 1995).

Hal ini didukung oleh Fengel dan Wegener (1995), yang menyatakan bahwa terdapat beberapa jenis reaksi utama lignin dengan asam peroksida di dalam media asam asetat yaitu adisi gugus-gugus hidroksil kepada cincin, dimetilisasi oksidatif, pembukaan cincin oksidatif, penggantian rantai samping, pemecahan ikatan $\beta$-arileter, dan epoksidasi struktur olefinik.

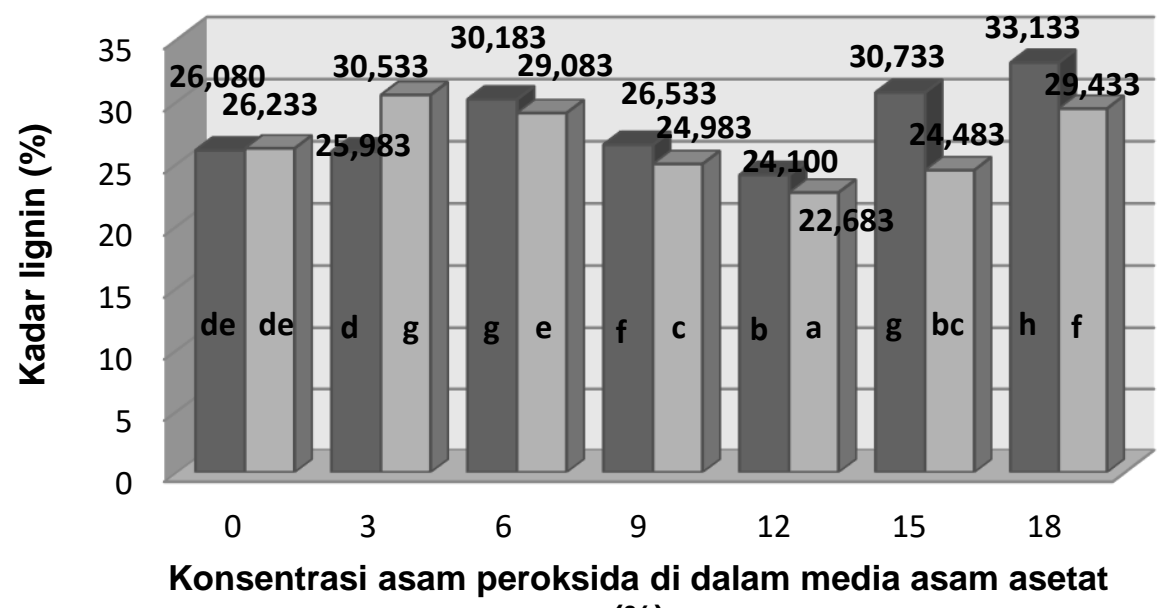

(\%)

- Lama pemasakan 3 jam $\quad \square$ Lama pemasakan 5 jam

Keterangan: angka-angka yang diikuti oleh huruf yang sama tidak berbeda nyata pada taraf 5\%

Gambar 3. Kadar lignin dengan penambahan konsentrasi asam peroksida di dalam media asam asetat sebanyak $0 \%$ sampai $18 \%$ dan lama pemasakan selam 3 jam dan 5 jam

\section{Warna}

Skor warna yang dihasilkan dari penelitian ini berkisar dari 1.1 sampai 5.9. Hasil analisis ragam menunjukkan bahwa penambahan asam peroksida di dalam media asam asetat, lama pemasakan dan interaksi keduanya berpengaruh sangat nyata terhadap skor warna pulp kertas koran bekas. Uji lanjut Duncan menunjukkan bahwa pulp kertas koran bekas dengan perlakuan asam peroksida di dalam media asam asetat $0 \%$ dan lama pemasakan selama 3 dan 5 jam berbeda nyata dengan pulp kertas koran bekas dengan perlakuan lainnya dan menghasilkan skor warna terendah, yaitu 1.1 (Gambar 4).

Peningkatan skor warna putih diduga karena adanya peningkatan konsentrasi asam peroksida di dalam media asam asetat yang berfungsi sebagai oksidator. Reaksi elektrofilik merupakan reaksi 
tahap awal di dalam proses pemutihan untuk mendegradasi sisa lignin yang ada di dalam pulp sehingga menurunkan kandungan lignin dan Reaksi ini diawali dengan pembentukan ion-ion radikal. Pembentukan ion ini hanya dapat bersifat stabil di dalam medium asam dan bereaksi di bawah kondisi dengan struktur fenolik dan non-fenolik. Namun, bahan kimia pemutih pada tipe radikal bebas dapat bereaksi tidak hanya di dalam medium asam tetapi juga dalam medium alkali. Tipe radikal bebas ini menyerang struktur fenolik dan olefinik. Reaksi elektrofilik awal menyerang melalui tipe radikal atau kation yang mengakibatkan pembentukan langsung sesuai dengan produk pengganti atau pembentukan pusat untuk reaksi selanjutnya dengan tipe anion sesuai dengan bahan kimia pemutih atau larutan. Pada kondisi asam, hidrogen peroksida sangat stabil, pada kondisi basa mudah terurai. Peruraian hidrogen peroksida juga dipercepat oleh naiknya suhu. Zat reaktif dalam sistem pemutihan dengan hidrogen peroksida dalam suasana basa adalah perhydroxyl anion (HOO-) (Fuadi dan Sulistya, 2008). Proses pemutihan menggunakan peroksida biasanya dilakukan kisaran waktu 30 menit hinga 4 jam. Pada suhu diatas $60^{\circ} \mathrm{C}$, peroksida merupakan bahan kimia pemutih yang efektif untuk meningkatkan derajat putih pulp mekanik dan semi mekanik tanpa harus kehilangan lignin dan rendemen secara signifikan.

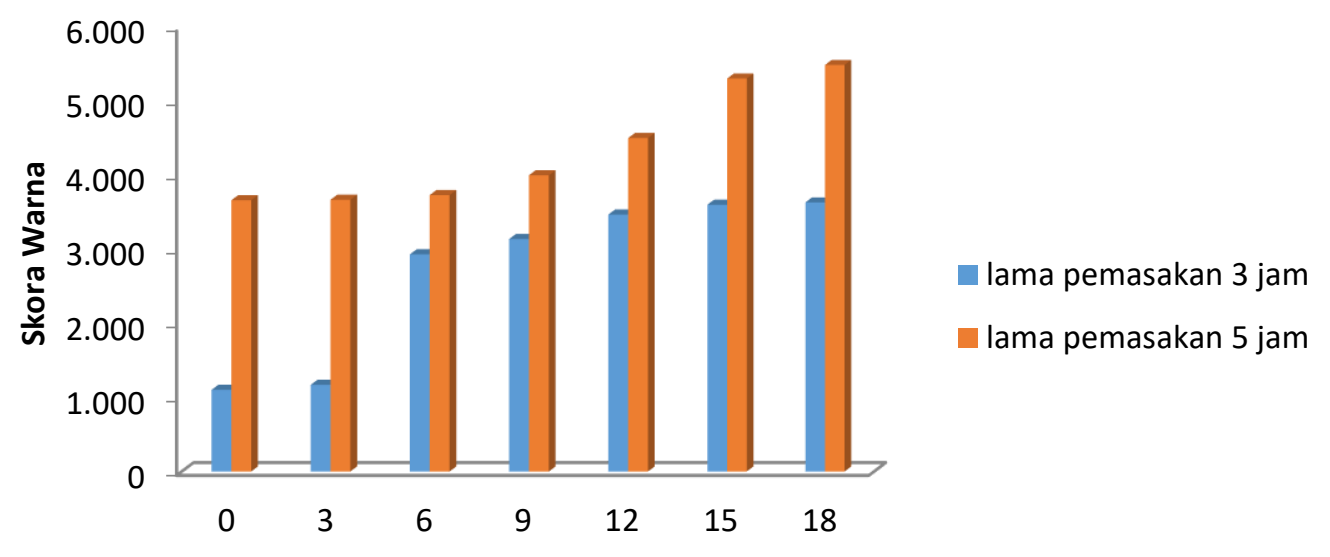

Konsentrasi asam peroksida di dalam media asam asetat (\%)

\section{KESIMPULAN}

1. Pemutihan pulp kertas koran bekas dengan menggunakan konsentrasi asam peroksida di dalam media asam asetat dan lama pemasakan yang berbeda berpengaruh sangat nyata terhadap sifat kimia (kadar hemiselulosa, selulosa dan lignin) dan warna pulp kertas koran bekas.

2. Hasil terbaik dapat diperoleh pada pemutihan dengan menggunakan konsentrasi asam peroksida di dalam media asam asetat $12 \%$ dan lama pemasakan 5 jam dengan kadar hemiselulosa 9.033\%; kadar selulosa $58.653 \%$; kadar lignin 22.683\%; dan skor warna 4.503 (agak putih).

\section{DAFTAR PUSTAKA}

Achmadi, S .S. 1990. Kimia Kayu. Departemen Pendidikan dan Kebudayaan. Direktoran Jendral Pendidikan Tinggi Pusat Antar universitas Ilmu Hayat. Institut Pertanian Bogor. $105 \mathrm{hlm}$.

Aremu, M. O., Aperolola, S. O and Dabonyan, O. O., (2015), 
Suitability of Nigerian Corn Husk and Plantain Stalk For Pulp and Paper Production, European Scientific Journal, Vol.11 (30), pp. 146-152.

Arifin. 2008. Industri Pulp Dan Kertas: Ancaman Baru Terhadap Hutan Alam Indonesia. wordpress.com/2008/01/19/industripulp-dan-kertas-ancaman-baruterhadap-hutan-alam-indonesia/

Batubara, R. 2006. Teknologi Bleaching Ramah Lingkungan. Fakultas Pertanian. Karya Tulis. Universitas Sumatera Utara. Hlm 1-6

Barr, C. 2001. The Financial Collapse of asi Pulp \& Paper: Moral Hazarddan Implication for Indonesia's Forest, dalam Asian Development Forum-3, Bangkok.

BIRO. 2001. Indonesia Pulp dan Paper Industry. Jakarta: PT Biro Data Indonesia.

Chang, H. M. 1995. Peracids As A Bleaching Agent: Basics. In: Proc. Emerging Pulping And Bleaching Tech. Workshop. Durham.

Datta, R. 1981. Acidogenic Fermentation of Linocellulose Acid Yield and Connvertion of Componens. Biotechnol. Bioeng 23. 21672170.

Deperindag dan APKI. 2001. Industri Pulp dan Kertas 1999-2003: Realisasi 1999-2000 dan Proyeksi 2001-2003. Jakarta: Direktorat Industri Pulp dan Kertas.

Edahwati, L. 2009. Proses deinkin Kertas Koran Bekas Menggunakan Hidrogen peroksida, Jurnal Kimia dan teknologi. ISSN 0216-163X. Hal 322-327.

Fengel, D dan Wegener, G. 1995. Kayu: Kimia, Ultrastruktur, Reaksi reaksi. Gadjah Mada University Press. Yogyakarta. 77-545.
Fuadi, A.M., dan Sulistyo, P. 2008. Pemutihan Pulp dengan Hidrogen peroksida. Jurnal reaktor, Vol. 12, No. 2. Hlm 123-128.

Fuadi, A.M., dan H. Sulistya. 2008, Pemutihan Pulp dengan Hidrogen Peroksida, Reaktor, 2(12), 123-128.

Hatakeyama, H, Nakano, M.J and Migita, N. 1986. Degradation of Cellulose with Peracetic Acid. Kogua Kgaku Zusshin71 (1), p: 153-156.Hill, R. T., Walsh, P. B., Hollie, J. A. Part I: Peracetic Acid An Effective Alternative For Chlorine Compound Free Delignification of Kraft Pulp. In: Proc. Tappi Pulp Conf., Boston, 1992. P.1219-1230.

Hidayati, S dan Zulferiyenni. 2006. Proses pemutihan dan pengaruhnya menggunakan asam peroksida di dalam media asam asetat terhadap sifat kimia dan derajat putih kertas koran bekas. Jurnal Lamina Media Publikasi ilmiah, Vol. 2, No 2 (7882).

Jayanudin, 2009, Pemutihan Daun Nanas Menggunakan Hidrogen Peroksida, Jurnal Rekayasa Proses Vol. 3, No 1.

Jääskeläinen, A. S. and , Poppius-Levlin, K. Carbohydrates in peroxyacetic acid bleaching. In: Proc. Interl. Pulp Bleaching Conf., Helsinki. 1998, p.423-428.

[Kemenhut] Kementerian Kehutanan. 2013. Statistik Kehutanan Indonesia 2012. Jakarta (ID): Kementerian Kehutanan.

Lawrence W, McKelvey R.D, Johnson D.C. 1980. The peroxyacetic acid oxidation of a lignin-related $\beta$-aryl ether. Svensk Papperstidn 83: 1118.

Mahagaonkar, M and Paul, B. 1995. Effect of the Deinking on Optical and Physical Properties of 
Secondary Fibre after Pulping and Flotation. APPITA, 4:6.

Madakadze, I.C., Radiotis, T., . Li, J., Goel, K and. Smith, D.L., (1999), Kraft Pulping Characteristics and Pulping Properties of Warm Season Grasses, Bioresource Technology, 69: 75-78.

Nevell, T.D daan Zeronian, S.H. 1985. Oxidant of cellulose in Cellulose Chemistry and Its applications, Ellis Hardwood Limited Chiccherter-West Sussex, p: 243-265.

Paraskevas, S. 1990. Ink RemovalVarious Methods and Their Effectiveness. Recycling Paper:From Fibre to Finished Product, 426-429.

Retnowati, D.S. 2008. Pemutihan enceng gondok menggunakan $\mathrm{H} 2 \mathrm{O} 2$ dengan katalisator natrium bikarbonat. Reaktor, Vol. 12, No. 1, Pp. 33-36

Rismijana, J, I.N Indriani dan T Pitariyani. 2003. Penggunaan Enzim SelulaseHemiselulase pada Proses Deinking Kertas Koran Bekas. Jurnal Matematika dan Sains, Vol. 8, No. 2:67-71.

Sjostrom, E. 1981. Kimia Kayu; Dasardasar dan Penggunaan. Edisi ke 2. Gajah Mada University Press. Yogyakarta. $390 \mathrm{Hlm}$.

Steel, R. G. D and Torrie, J. H. 1990. Prinsip dan Prosedur Statistik, Suatu
Pendekatan Biometrik. Gramedia. Jakarta.

Sun R.C, Tomkinson J, Zhu W, Wang SQ . 2000. Delignification of maize stems by peroxymonosulfuric acid, peroxyformic acid, peracetic acid, and hydrogen peroxide. 1. Physicochemical and structural characterization of the solubilized lignins. J Agric Food Chem 48: 1253-1262.

Wildan A, Abdullah, Priyanto A, 2010, Studi Proses Bleaching Serat Kelapa Sebagai Reinforced Fiber, Seminar Rekayasa Kimia dan Proses, ISNN : 1411-4216

Yamani M. 2011. Strategi perlindungan hutan berbasis hukum lokal di enam komunitas adat daerah bengkulu. Jurnal Hukum. 2:175-192.

Yves L, Yumiko U, Michael S, Arif B, Budi S, Oki H. 2010. Eco-floristic sectors and deforestation threats in Sumatra: identifying new conservation area network priorities for ecosystem-based land use planning. Biodiversity \& Conservation. 19 (4):1153-1174.

Zuidar, A.S; Hidayati, S dan Pulungan, R.J.A. 2014. Kajian Delignifikasi Pulp Formacell Dari Tandan Kosong Kelapa Sawit Menggunakan Hidrogen Peroksida $\left(\mathrm{H}_{2} \mathrm{O}_{2}\right)$ Dalam Media Asam Asetat. Jurnal Teknologi Industri dan Hasil Pertanian Volume 19 No.2, P. 194204. 